\title{
Lung protective ventilation in a non-ARDS setting: A tertiary centre survey and audit
}

Buyse Klaas, Van der Laenen Margot, Mesotten Dieter, Eertmans Ward. Department of Anesthesiology, Intensive Care Medicine, Emergency Care and Pain Therapy Ziekenhuis Oost Limburg, Genk, Belgium

\section{BACKGROUND AND GOAL OF STUDY}

Lung protective ventilation (LPV), with tidal volume (TV) $6 \mathrm{ml} / \mathrm{kg}$ ideal body weight (IBW), improved outcome in patients with acute respiratory distress syndrome ${ }^{1}$. Also after major abdominal surgery LPV (TV: $6-8 \mathrm{ml} / \mathrm{kg}$ IBW) reduced the rate of complications ${ }^{2}$. While in guidelines LPV is recommended, its acceptance and compliance rate is yet unclear.

\section{MATERIALS AND METHODS}

A survey among ICU healthcare workers (staff: 31, trainees: 34, nurses: 99) of our 36-bed mixed ICU assessed their understanding of calculating IBW and determining the initial tidal TV by means of 3 cases (BMI 19, 26, 39). We also assessed their level of LPV approval in a non-ARDS setting.

To audit the daily practice of LPV, a retrospective analysis of ventilator settings was performed in all cardiac surgery patients $(n=240)$ who were admitted to the ICU between June and November 2016. TVs, measured 2 hours after arrival in the ICU, were analysed in correlation with quality cut-offs for LPV: $>8$ $\mathrm{ml} / \mathrm{kg} \mathrm{IBW}$ and $>10 \mathrm{ml} / \mathrm{kg} \mathrm{IBW}$.

\section{RESULTS}

28 (90\%) staff, 28 (82\%) trainees and $43(43 \%)$ nurses responded to the survey. Over all cases 35 (42\%), 17 $(20 \%)$ and $54(42 \%)$ staff, trainees and nurses respectively used TV $>8 \mathrm{ml} / \mathrm{kg}$. $4(5 \%), 0(0 \%)$ and 9 (5\%) staff, trainees and nurses respectively used TV > $10 \mathrm{ml} / \mathrm{kg}$ IBW. Trainees (20\%) used less TV of $>8 \mathrm{ml} / \mathrm{kg}$ IBW then staff $(42 \%)$ and nurses $(42 \%)(P<0.002) .23$ $(82 \%), 28(100 \%)$ and $35(81 \%)$ staff, trainees and nurses respectively approved LPV in a non-ARDS setting.

In the retrospective analysis (Fig 1 ) all 240 patients were on volume controlled ventilation. Mean

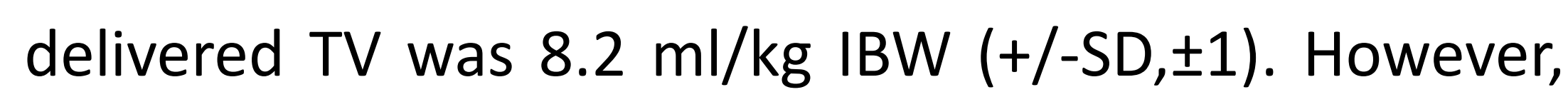
$139(57.9 \%)$ patients received TV of $>8 \mathrm{ml} / \mathrm{kg}$ IBW and $16(6.7 \%)$ TV of $>10 \mathrm{ml} / \mathrm{kg}$ IBW. TV $>8 \mathrm{ml} / \mathrm{kg}$ IBW occurred in $46(68 \%)$ of obese $(68 / 240)$ patients ( $P=0.06)$. 50/60 (83\%) females received TV $>8 \mathrm{ml} / \mathrm{kg}$ IBW in contrast to $89 / 180(49 \%)$ males $(P<0.001)$.

\section{CONCLUSIONS}

Although the majority of our ICU healthcare workers advocated LPV in a non-ARDS setting, a too large proportion of patients, notably females and obese, were exposed to high TV.

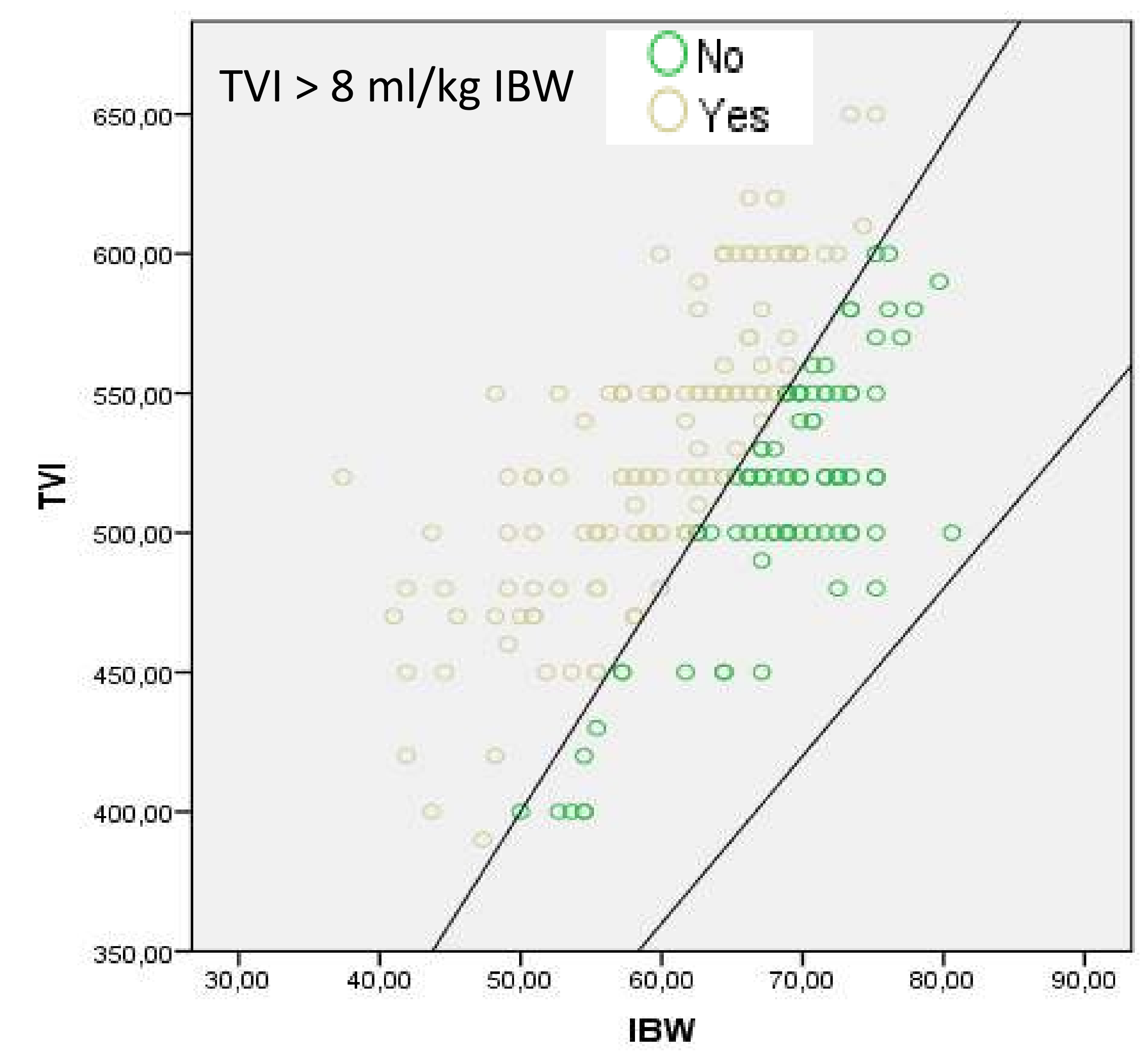

Fig 1: Retrospective analysis

\section{REFERENCES}

1 , Ventilation with lower tidal volumes as compared with traditional tidal volumes for acute lung injury and the acute respiratory distress syndrome. The acute respiratory distress syndrome network. N Engl J Med. 2000;342:1301-8.

2, A trial of intraoperative low-tidal-volume ventilation in abdominal surgery Futier E, Constantin JM, Paugam-Burtz C, Pascal J, Eurin M, Neuschwander A, et al.. N Engl J Med. 2013;369:428-37. 